\title{
On the Mechanism of Oligomer Formation in Condensations of Alkyl Cyanoacetates with Formaldehyde
}

\author{
J. M. ROONEY \\ Loctite (Ireland) Limited, Whitestown Industrial Estate, \\ Tallaght, Co. Dublin, Ireland. \\ (Received December 11, 1980) \\ KEY WORDS Alkyl Cyanoacetates / Formaldehyde / Condensation / \\ Anionic Polymerization / Cyanoacrylate / Chain Transfer /
}

Industrial synthetic routes to the production of alkyl cyanoacrylate monomers frequently involve base-catalyzed condensations of alkyl cyanoacetates with formaldehyde to form low molecular weight polymers. ${ }^{1}$ Early studies attributed polymer formation to a stepwise condensation ${ }^{2}$ of the form, ${ }^{3.4}$
Since the apparent activation energy of the overall process was found to be similar to that of the condensation of diethyl dicyanoglutarate with formaldehyde, the addition of diethyl dicyanoglutarate to formaldehyde is assumed to be the ratedetermining step.

$$
\begin{array}{ll}
\stackrel{\mathrm{CN}}{1} \\
\stackrel{\mathrm{C}}{\mathrm{C}} \mathrm{H}_{2} \\
1 \\
\stackrel{\mathrm{COOR}}{\mathrm{C}}
\end{array} \stackrel{\mathrm{HCHO}}{\underset{\mathrm{C}}{\mathrm{C}} \mathrm{HCH}_{2} \mathrm{OH}}
$$
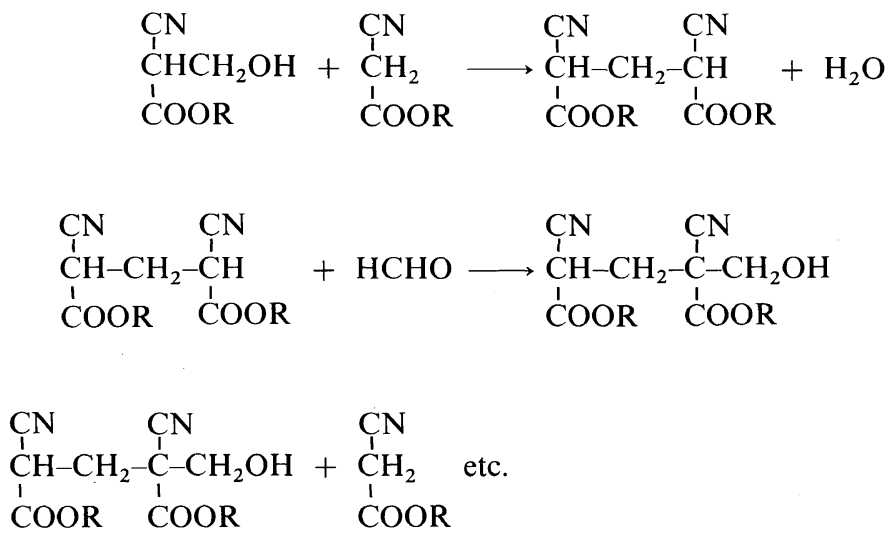

Subsequently, a kinetic study of the reaction of formaldehyde with methyl cyanoacetate ${ }^{5}$ yielded evidence that methyl cyanoacrylate monomer is an intermediate in oligomer formation. Experiments with methylolated methyl 2-cyanopropionate indicated that water evolution did not involve nucleo- philic displacement of the hydroxyl group by cyanoacetate anion. Instead, it is postulated that the essential step in water evolution is the formation of methyl cyanoacrylate. Under basic conditions, alkyl cyanoacrylates polymerize rapidly by an anionic mechanism. ${ }^{6}$ However the low observed molecular 
weights of the cyanoacrylate oligomers are thought to preclude this mechanism and a Michael addition process has been proposed as the propagation step with chain lengths being governed by steric hindrance.

Recent work by Pepper and Ryan ${ }^{7}$ has shown that base-initiated polymerizations of butyl cyanoacrylate monomer in butyl cyanoacetate solvent at $20^{\circ} \mathrm{C}$ lead to the formation of low molecular weight polymers $\left(M_{n} \sim 5,000-10,000\right)$, presumably by a chain transfer mechanism of the type:
In the present communication, experiments are described which demonstrate that oligomer formation in condensations of alkyl cyanoacetates with formaldehyde is consistent with an anionic polymerization mechanism in which polymer chain lengths are determined by chain transfer to the alkyl cyanoacetate.

\section{EXPERIMENTAL}

Condensations of alkyl cyanoacetates with form-

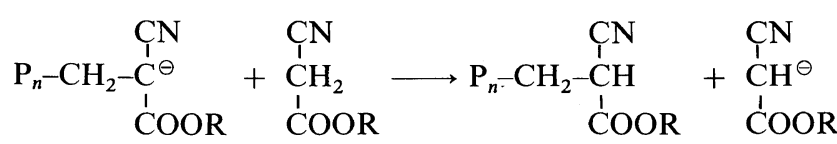<smiles>[R]OC(=O)C(=C[CH+])C(=O)O[R20]</smiles>

aldehyde were conducted in glass or stainless steel vessels fitted with Dean-Stark reflux traps. A typical reaction charge included $113 \mathrm{~g}$ ethylcyanoacetate, $30 \mathrm{~g}$ paraformaldehyde, $0.34 \mathrm{~g}$ piperidine and $100 \mathrm{~g}$ heptane. During the reactions, the temperature rose gradually from $80^{\circ} \mathrm{C}$ to $100^{\circ} \mathrm{C}$. Oligomer samples were removed and neutralized with a solution of methanesulfonic acid in acetone. The corresponding amount of water evolved from the condensation was noted and used to compute the percentage conversion of the cyanoacetate. Oligomers were isolated by evaporation and molecular weights were determined on methylene dichloride solutions in a Waters 244 Liquid Chromatograph fitted with $\mu$ Styragel columns $(1000 \AA, 2 \times 500 \AA$, and $2 \times$ $100 \AA$ ). A sample of the dicyanoglutarate was isolated by preparative chromatography and characterized by infrared and NMR spectroscopy. This sample was used to calibrate the liquid chromatograph. Oligomers were analyzed by NMR spectroscopy and found to consist of structural homologs of the glutarate. Thermal decompositions of paraformaldehyde were conducted in air with $2 \mathrm{mg}$ samples on a Perkin-Elmer TGS-1 thermobalance equipped with a Model UU-1 temperature program control.

\section{RESULTS AND DISCUSSION}

Under proper conditions, chromatographic separation of the various oligomers in cyanoacetateformaldehyde reaction products was obtained.

Figure 1 depicts liquid chromatograms of samples taken during a run with heptane as the azeotrope-forming solvent. Samples of diethyl dicyanoglutarate were chromatographed to calibrate the system and from the clearly defined low molecular weight oligomers, a semilogarithmic plot of molecular weight as a function of elution volume was constructed as shown in Figure 2.

The mechanism of cyanoacrylate monomer formation has been established by Smith $^{5}$ and involves a rapid equilibrium between base (B) and alkyl cyanoacetate (CNA) to form an anion $\left(\mathrm{CNA}^{\ominus}\right)$ which then participates in a Knoevenagel condensation to form a methylol compound. This methylol compound (CNAOH) undergoes dehydration to yield the free cyanoacrylate monomer (CA). For the present case, in which formaldehyde is provided by thermal decomposition of paraformaldehyde, the kinetic scheme may be outlined as follows:

$$
\begin{array}{ll}
\mathrm{B}+\mathrm{CNA} & \rightleftharpoons \mathrm{CNA}^{\ominus}+\mathrm{HB}^{\oplus} \\
\left(\mathrm{CH}_{2} \mathrm{O}\right)_{n} & \stackrel{k_{2}}{\longrightarrow} \mathrm{CH}_{2} \mathrm{O}
\end{array}
$$




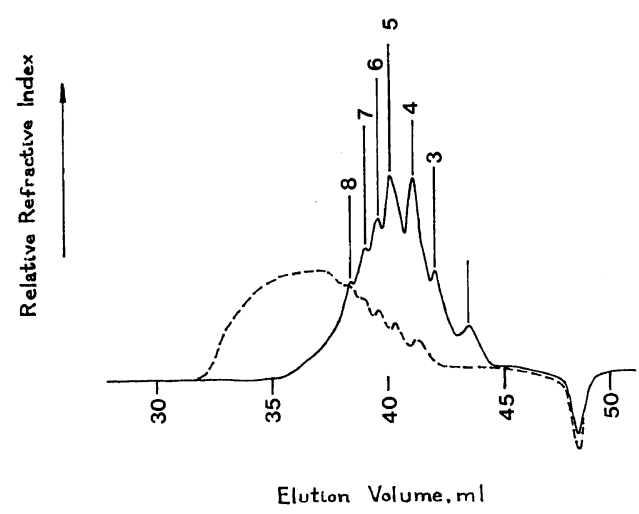

Figure 1. Liquid chromatograms of ethyl cyanoacrylate oligomers from run $428-31$ at (-) $26 \%$ and $(---) 90 \%$ cyanoacetate conversion. HPLC conditions: $\mathrm{CH}_{2} \mathrm{Cl}_{2}$ solvent at $1.5 \mathrm{ml} \mathrm{min}{ }^{-1} ; \mu$-styragel columns $(1 \times 1000 \AA ; 2 \times 500 \AA ; 2 \times 100 \AA)$.

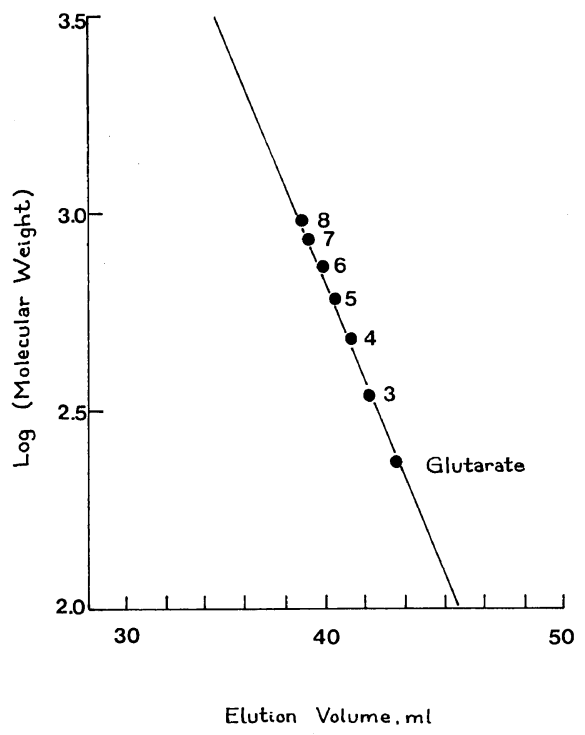

Figure 2. HPLC calibration plot for ethyl cyanoacrylate oligomers derived from Figure 1 .

$$
\begin{array}{ll}
\mathrm{CNA}^{\ominus}+\mathrm{CH}_{2} \mathrm{O} & \stackrel{k_{3}}{\longrightarrow} \mathrm{CNAO}^{\ominus} \\
\mathrm{CNAO}^{\ominus}+\mathrm{HB}^{\oplus} & \stackrel{k_{4}}{\longrightarrow} \mathrm{CNAOH}+\mathrm{B} \\
\mathrm{CNAOH} & \stackrel{k_{5}}{\longrightarrow} \mathrm{CA}+\mathrm{H}_{2} \mathrm{O}
\end{array}
$$

In reactions between formaldehyde and alkyl cyanoacetate, the rate-determining step is shown to be step 3. Results of a series of experiments in which the effect of the rate of thermal decomposition of

\begin{tabular}{|c|c|c|}
\hline \multirow[t]{2}{*}{ Run No. } & $\begin{array}{l}\text { Half-order decomposition } \\
\text { rate constant }\end{array}$ & \multirow{2}{*}{ Oligomer $M_{n}$} \\
\hline & $\min ^{-1}$ & \\
\hline 519-38 & $0.064 \pm 0.016$ & 780 \\
\hline 519-39 & $0.092 \pm 0.027$ & 790 \\
\hline $519-40$ & $0.114^{-}$ & 780 \\
\hline
\end{tabular}

Table I. The effect of paraformaldehyde decomposition rate on ethyl cyanoacrylate oligomer molecular weight

paraformaldehyde on oligomer molecular weight was examined are shown in Table I. Rates of thermal decomposition in air at $90^{\circ} \mathrm{C}$ for three different samples of paraformaldehyde were determined on a thermal balance. Rate constants were derived from the slopes of half-order plots of weight loss as a function of time. Condensations of these samples with ethyl cyanoacetate under identical conditions yielded oligomers of similar molecular weights, leading to the conclusion that the rate of thermal decomposition of paraformaldehyde does not significantly affect cyanoacrylate oligomer molecular weight.

Anionic polymerization of cyanoacrylate monomers in the presence of chain transfer agents such as alkyl cyanoacetates follows the equations:

$\begin{array}{lll}\mathrm{CA}+\mathrm{CNA}^{\ominus} \stackrel{k_{6}}{\longrightarrow} \mathrm{P}_{1}^{\ominus} & \text { (initiation) } \\ \mathrm{P}_{n}^{\ominus}+\mathrm{CA} & \stackrel{k_{7}}{\longrightarrow} \mathrm{P}_{n+1}^{\ominus} & \text { (propagation) (7) } \\ \mathrm{P}_{n}{ }^{\ominus}+\mathrm{CNA} & \stackrel{k_{8}}{\longrightarrow} \mathrm{P}_{n}+\mathrm{CNA}^{\ominus} & \text { (transfer) }\end{array}$

These ionic reactions may safely be assumed to be solvated by the cyanoacetate and oligomers (which form a viscous liquid at temperatures above $80^{\circ} \mathrm{C}$ ) in systems with a heptane azeotrope due to the marked differences in dielectric constant and electron donor activity between these solvents. Assuming that the concentrations of the species $\mathrm{CNA}^{\ominus}, \mathrm{P}_{n}{ }^{\ominus}$ and $\mathrm{CA}$ are constant (since the CA polymerizes as rapidly as it is formed in step 5), the rate of polymer chain propagation may be written as,

$$
R_{\text {prop }}=k_{6}[\mathrm{CA}][\mathrm{CNA}]^{\ominus}+k_{7}\left[\mathrm{P}_{n}^{\ominus}\right][\mathrm{CA}]
$$

while the rate of chain transfer is expressed as,

$R_{\text {trf }}=k_{8}\left[\mathrm{P}_{n}^{\ominus}\right][\mathrm{CNA}] \equiv k_{6}[\mathrm{CA}][\mathrm{CNA}]^{\ominus}$

Consequently, the instantaneous degree of polym- 
erisation at any moment is given by equation 11 ,

$$
D P_{\text {inst }}=1+\frac{k_{7}[\mathrm{CA}]}{k_{8}[\mathrm{CNA}]}
$$

The average degree of polymerization is obtained by integrating with respect to cyanoacetate concentration.

$$
\overline{D P}=1+\frac{\frac{k_{7}}{k_{8}}[\mathrm{CA}] \ln \frac{[\mathrm{CNA}]_{0}}{[\mathrm{CNA}]_{\mathrm{f}}}}{[\mathrm{CNA}]_{0}-[\mathrm{CNA}]_{\mathrm{f}}}
$$

which may be simplified as equation 13 ,

$$
\overline{D P}=1+\frac{K \ln \frac{[\mathrm{CNA}]_{0}}{[\mathrm{CNA}]_{\mathrm{f}}}}{[\mathrm{CNA}]_{0}-[\mathrm{CNA}]_{\mathrm{f}}}
$$

In Figure 3, the number-average degrees of polymerization for a series of oligomer samples withdrawn from condensations of paraformaldehyde and ethyl cyanoacetate in heptane are plotted as functions of cyanoacetate conversion. The solid line is derived from equation 13. In Figure 3, $[\mathrm{CNA}]_{0}$ is taken as $9.0 \mathrm{~mol} \mathrm{dm}^{-3}$, the value for bulk ethyl cyanoacetate at $80^{\circ} \mathrm{C}$. The value of $K$ was chosen to give the best fit for the system. The dashed line represents the theoretical degree of polymerization calculated from stepwise condensation kinetics, $\left(\overline{D P}_{n}=\right.$ $\left.[\mathrm{CNA}]_{0} /[\mathrm{CNA}]_{0}-[\mathrm{CNA}]_{\mathrm{f}}\right)$.

The data indicate that the nature of oligomer formation in cyanoacetate-formaldehyde condensations is consistent with an anionic polymerization mechanism and not consistent with a stepgrowth mechanism. In a Michael addition system for which steric hindrance determined polymer chain length, a steady increase in polymer molecular weights during the reaction would not be expected.

\section{REFERENCES}

1. F. B. Joyner and N. H. Shearer, Jr., U.S. Patent

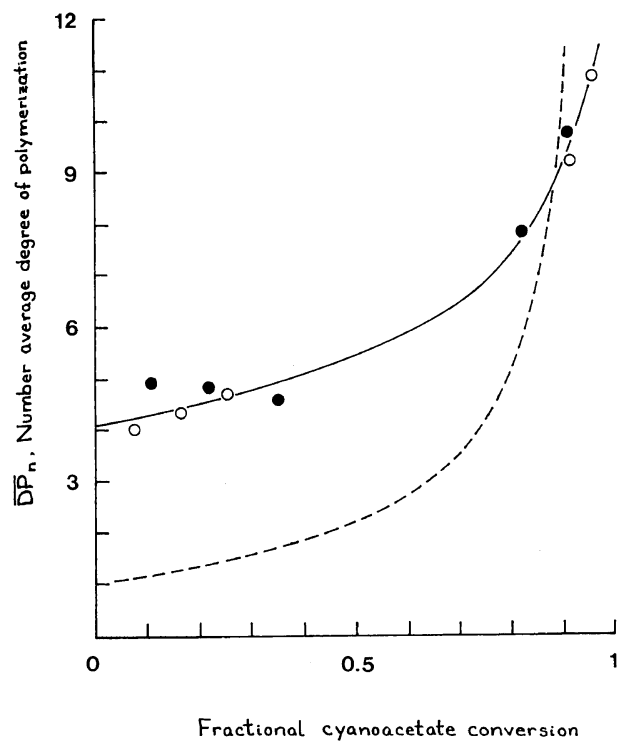

Figure 3. Ethyl cyanoacrylate oligomer molecular weight as a function of cyanoacetate conversion during condensations of ethyl cyanoacetate with formaldehyde in the presence of heptane. ( $O$, run 428-31; - run $428-32 ;-$, derived from eq 13 with $(\mathrm{CNA})_{0}=$ $9.0 \mathrm{~mol} \mathrm{dm}^{-3}$ and $K=28 \mathrm{~mol} \mathrm{dm}^{-3} ;---$ derived from $\left.\overline{D P}_{n}=[\mathrm{CNA}]_{0} /\left([\mathrm{CNA}]_{0}-[\mathrm{CNA}]_{\mathrm{f}}\right)\right)$.

2,756,251 (to Eastman Kodak Co.) (July 24, 1956).

2. G. F. Hawkins and H. F. McCurry, U.S. Patent 3,254,111 (to Eastman Kodak Co.) (May 31, 1966).

3. M. Yonezawa, S. Suzuki, H. Ito, and K. Ito, Yuki Gosei Kagaku Kyokai Shi, 25, 311 (1967).

4. M. Yonezawa, Yuki Gosei Kagaku Kyokai Shi, 30, 823 (1972).

5. D. R. Smith, Ph.D. Thesis, Northeastern University (1972).

6. E. F. Donnelly, D. S. Johnston, D. C. Pepper, and D. J. Dunn, J. Polym. Sci., Polym. Lett., 15, 399 (1977).

7. D. C. Pepper and B. Ryan, personal communication. 